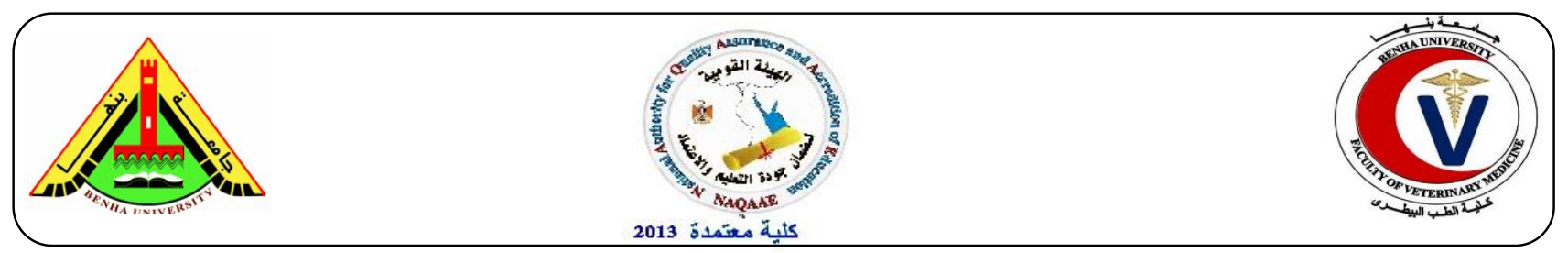

\title{
Comparative immune evaluation of inactivated Derzsy virus disease vaccine in SPF chicken and Muscovy duck
}

\author{
Alaa Ramadan.I., M.M Elsafty, Mohammed Abd-elkhalek, Reem A. Suliman \\ Central Laboratory for Evaluation of Veterinary Biologics, Agriculture Research Center, Abbasia, Cairo Egypt.
}

\section{A B S T R A C T}

Objective: Assessment the efficacy of commercial inactivated duck parvovirus vaccine in conventional ducklings by monitoring the antibody response of domestic Muscovy ducks after subcutaneous immunization and comparing the humoral immune response between vaccinated Muscovy ducklings and vaccinated SPF chicks using ELISA. Two separate vaccination experiments, here after referred to as experiments $\mathrm{A}$ and $\mathrm{B}$, with an identical experimental design were performed to study the efficacy of different three batches of commercial inactivated Parvovirus vaccine against Derzsy's disease.

Methods: In the first experiment (A): One hundred and five susceptible Muscovy ducks one week old were vaccinated with the recommended dose $(0.2 \mathrm{ml} / \mathrm{bird})$ via subcutaneous route $(\mathrm{S} / \mathrm{C})$ (twenty ducks for each batch) and fifteen ducks were kept without vaccination as a non- vaccinated control. Another group of ducks (ten ducks for each batch) were vaccinated with double the recommended vaccination dose via (s/c) and served as safety group.

In the second experiment (B): One hundred and five specific pathogen free chicks of three weeks old were vaccinated following the same procedures the vaccine was injected with $0.2 \mathrm{ml} / \mathrm{bird}$ subcutaneously in the dorsal region of the neck (twenty chicks for each batch). Other fifteen chicks were kept in separate isolator as non-vaccinated negative control. Another group of chicks (ten SPF chicks for each batch) were vaccinated with double the recommended vaccination dose via $\mathrm{S} / \mathrm{C}$ and served as safety group.

Results: The monitoring of the humeral immune response of both vaccinated waterfowl and SPF chicks were estimated by enzyme-linked ImmunoSorbant assay (ELISA). Comparing the humeral immune response of both vaccinated waterfowl and SPF chicks by ELISA showed that protective serum samples for GPV/MDPV. Results of serum samples of four weeks post vaccinated Muscovy ducks and SPF chicks were positive for different three vaccine batches GPV/MDPV antibodies of four weeks PV. 
Conclusion: The present study findings underlines that Muscovy ducks are the susceptible host for parvovirus up to approximately six weeks of age while SPF chicks is non susceptible host for parvovirus and we used it as a model for production of humeral antibodies.

Keywords: Derzsy virus disease vaccine, Muscovy ducks, SPF chicks, enzyme-linked ImmunoSorbant assay.

(http://www.bvmi.bu.edu.eg) $\quad$ (BVMJ-36(1): 12-22, 2018)

\section{INTRODUCTION}

Although chickens and turkeys comprise the majority of poultry species seen by the veterinary practitioner, occasionally waterfowl such as ducks and geese are encountered. One feature that is unique to waterfowl is that their environment usually involves the presence of man-made or natural bodies of water, and this may enhance the co-mingling of free-living waterfowl species with the domestic flock and ultimately, promote disease transmission. Additionally, environmental conditions may also influence disease manifestation in domestic waterfowl (Palya, 2011).

Waterfowl parvoviruses cause serious economic loss to waterfowl production worldwide (Glávits et al., 2005; Grzegorz et al., 2009). They also cause a highly contagious disease affecting goslings (Anser anser domestica) and Muscovy ducklings (Cairina mos-chata). They can be divided into two species: goose parvovirus (GPV) and Muscovy duck parvovirus (MDPV) (Palya, 2013). Muscovy duck parvovirus (MDPV) was first isolated from Muscovy ducks in the west of France in the autumn of 1989 (Jestin 1990, 1991, Jestin et al., 1991a). Although the host range of GPV (geese and Muscovy ducks) and MDPV (Muscovy ducks) differs, the disease is similar for both viruses. Clinical signs depend on the age and the immune status of infected goslings and Muscovy ducklings. An acute disease may develop in susceptible animals aged less one week with anorexia, polydipsia, weakness and prostration, leading to death within a few days (up to 100 per cent mortality). In susceptible birds aged between one and three weeks, the form of the disease can be acute, subacute or chronic, the morbidity reaching 100 per cent and the mortality $10-60$ per cent. The disease is characterized by locomotor dysfunction, stunting, abnormal feather development, reduced food intake, marked growth retardation, ocular and nasal discharge, diarrhoea and death in Muscovy ducks (Gough 2008, Palya 2013). Infection after four weeks rarely led to clinical signs, although a 'late form' of the disease may occur in older birds (Gough 2008). The disease is transmitted by direct or indirect contact with infected birds. Vertical transmission and egg shell contamination also occur, resulting in hatchery contamination in disease-free flocks (Gough 2008, Palya 2013). Parvovirus infects rapidly dividing cells; this is why clinical form of the disease occurs only in young birds, up to approximately six weeks of age. Nevertheless, infection with other immunosuppressive viruses (reovirus, cicrovirus) and mycoplasmas tends to aggravate the clinical disease by their 
synergistic effect and prolongs the sensitivity period to the clinical manifestation of the disease up to nine weeks of age. After this susceptible period, the birds can still be infected which causes serological response without clinical symptoms. The disease may be complicated with secondary bacterial pathogens: $E$. coli, Streptococcus spp, Pasteurellas etc. (Palya, 2011).

Clinical diagnosis is insufficient, especially during the chronic phase of the disease, and laboratory confirmation is necessary. Several diagnostic methods have been employed for the detection of both GPV or MDPV antigen and their antibodies, including agar gel precipitation, virus neutralization tests (Gough, 1984), Western blotting assays (Wang et al., 2005), virus antigen-based enzyme-linked immunosorbent assays (ELISA) (Jestin et al., 1991a; Kardi and Szegletes, 1996), a plaque neutralization assay (Takehara et al., 1994), an indirect fluorescent antibody test (Takehara et $a l ., 1999)$, and polymerase chain reaction (PCR) for the rapid detection of GPV DNA (Limn et al., 1996). All of these are effective and accurate methods of detecting viral infections, Virus antigen-based serologic tests have been reported during screenings for GPV infection (Jestin et al., 1991a; Kardi and Szegletes, 1996), but whole-virus purification requires the propagation of large quantities of virus in eukaryotic systems and depends on difficult and expensive processes. Currently, a rapid and simple diagnosis is required to detect highly contagious GPV or MDPV infection. Parent flocks could be monitored for antibody titers after vaccination against GPV or MDPV to determine whether titers are high enough for the protection of offspring from infection.
Since GPV and MDPV are very resistant to physical and chemical inactivation (Gough 2008, Palya 2013), and thus difficult to eliminate, vaccination of breeding flocks and their progeny is required to reduce the impact of the disease. Vaccination against Derzsy's disease relies on attenuated live or inactivated vaccines, while only inactivated vaccines are available against Muscovy duck parvovirosis (Kisary et al., 1978, Fournier and Gaudry 1992, Takehara et al., 1995). The live vaccines contain attenuated goose parvovirus, which can stimulate rapid immune response and protection in maternal antibody-free animals. Maternally derived antibodies (MDA), even at a very low level, is able to neutralize the live vaccine thus preventing it to stimulate immune-response. Traditionally, live attenuated vaccines are known to induce a quick onset of immunity in susceptible birds, while inactivated vaccines induce a slow immune response, but are less sensitive to the interference with maternal antibodies than live vaccines (Kisary 1977, Takehara et al., 1995). Inactivated vaccines (also called 'killed') contain the whole parvovirus antigens either in the monovalent (goose parvovirus) or bivalent (both goose and Muscovy duck parvovirus) form (Palya, 2011). Generally, vaccines induce high and uniform levels of protection after administration. However, vaccines must meet numerous strict quality, efficacy and safety criteria. The criteria for veterinary vaccines are well regulated by several bodies and testing requirements have been established for potency, efficacy, safety and purity (Alexander, 1988). The protective efficacy of a vaccine depends on its capability to induce a vigorous and long-lasting immune response. Chickens are considered the most widely studied avian species showing some 
differences in immunological response (AbdAlla et al., 2017).

This study was initiated to evaluate the efficacy of a commercial inactivated ParvoDerzsy vaccine (three different batches of inactivated Parvo Derzsy virus vaccine was obtained from Central Laboratory for Evaluation of veterinary Biologics (CLEVB), Cairo, Egypt. By comparing the humoral immune response of both vaccinated ducks and SPF chicks.

\section{MATERIAL AND METHODS}

\subsection{Birds:}

Muscovy ducks: One hundred and five, one week old susceptible Muscovy ducks, nonvaccinated against parvoviruses at the hatchery, were purchased, Ducks were housed in separate rooms, in contained facilities, standard battery cages. Ducks were fed on a high-quality commercial dry ration with unlimited access to water. Ducks were identified by individual numbered wing rings.

2.2.Specific pathogen-free (SPF) chicks: One hundred and five SPF chicks three weeks old were obtained from National Project for Production of Specific Pathogen Free Eggs, Kom Oshim, Fayom, Egypt. All birds were kept in biosafety isolators.

2.3.Parvo Derzsy virus vaccine: Three different batches of inactivated Parvo Derzsy virus vaccine was obtained from Central Laboratory For Evaluation of veterinary Biologics (CLEVB), Cairo, Egypt.

2.4.Enzyme linked immunosorbant assay kit: Commercial Geese parvovirus antibody ELISA kit (Shanghai Coon Koon Biotech., Ltd) (LOT number: 201809).

2.5. SPF Embryonated chicken eggs (ECE): One day old specific pathogen free (SPF). The eggs were obtained from the National Project for Production of Specific Pathogen Free Eggs, Koum Oshim, Fayom, Egypt. It kept in the egg incubator at $37^{\circ} \mathrm{c}$ with humidity $40-60 \%$ till the age of 9-11 day old and were used for completion of inactivation of the tested vaccine.

2.6. Quality control of the vaccine:

1. Identity: The vaccine strains are indirectly identified by detection of the goose and duck parvovirus neutralizing or precipitating antibodies in sera of vaccinated bird, or indirectly identified by detection of the virus antigen with Agar gel precipitation test (AGPT).(Gough,1984).

2. Sterility: The vaccine was tested for freedom of variable bacteria and Fungi. (Egyptian standard regulations for evaluation of veterinary biologics, $3^{\text {rd }}$ Edition, 2017).

3. Completion of inactivation: $2 / 5$ of the vaccine dose was inoculated into each of five susceptible 9-10 day -old SPF ECE via allantoic cavity. incubation of the eggs at $37^{\circ} \mathrm{c}$ with daily examination for 7 days. Examination of each embryo for goose and duck parvovirus infection gross lesions which represent in form of hemorrhages and ochre colored liver from each egg and test for the presence of the virus by AGP test. (Egyptian standard regulations for evaluation of veterinary biologics, $3^{\text {rd }}$ Edition, 2017). 
4. Safety: Ten susceptible Muscovy ducks and ten SPF chicks for each batch were vaccinated with $(0.4 \mathrm{ml})$ double the recommended vaccination dose $(0.2 \mathrm{ml})$ via recommended route $(\mathrm{S} / \mathrm{C})$ and the birds were observed for 14 days for any undesirable local or systemic reaction. (Egyptian standard regulations for evaluation of veterinary biologics, 3rd Edition, 2017).

\subsection{Experimental design for evaluation of each} batch of the inactivated vaccine (Potency test):

1- Group 1: twenty susceptible Muscovy ducks one week old were vaccinated with $0.2 \mathrm{ml} / \mathrm{bird}$ via subcutaneous route.

2- Group 2: ten susceptible Muscovy ducks for each batch) were vaccinated with double the recommended vaccination dose $(0.4 \mathrm{ml} / \mathrm{bird})$ via $\mathrm{s} / \mathrm{c}$ route and served as safety group.

3- Group 3: fifteen ducks were kept without vaccination as a non- vaccinated control.

4- Group 4: twenty of specific pathogen free chicks of three weeks old were vaccinated with $0.2 \mathrm{ml} \quad /$ bird subcutaneously in the dorsal region of the neck.

5- Group 5: ten SPF chicks were vaccinated with double the recommended vaccination dose $(0.4 \mathrm{ml} / \mathrm{bird})$ via $\mathrm{s} / \mathrm{c}$ route and served as safety group.

6- Group 6: fifteen chicks were kept in separate isolator as non-vaccinated negative control.

\subsection{Compliance with ethics requirements:}

The birds care and experimental protocols were in compliance with guidelines of ethical standards released by Cairo University policy on animal care and use. All efforts were made to ensure ethical and humane treatment of the birds.

Collection of serum samples for determination of antibody titers after vaccination (Sampling):

Sera were collected from the vaccinated birds at four weeks post vaccination. Approximately 1.5 to $2 \mathrm{ml}$ of blood was collected from the jugular vein with a $3 \mathrm{ml}$ syringe. The syringe was laid nearly horizontally until the blood clotted. After clotting, the syringe was returned to a vertical inverted position to permit the serum to ooze out. The samples were then kept at $37{ }^{\circ} \mathrm{C}$ for one hour and left overnight at $4^{\circ} \mathrm{c}$ before the serum was separated. The separated serum was transferred to cryo-vials, labelled, and stored at $-20{ }^{\circ} \mathrm{C}$ until the ELISA was performed.

Detection of antibodies in collected serum samples by Enzyme-linked immunosorbent assay: The ELISA was performed according to the procedures recommended by the manufactures (Shanghai Coon Koon Biotech., Ltd) as follow: Briefly pre-coated with viral antigen Microtitre plates were incubated with $50 \mu \mathrm{l}$ of negative and $50 \mu \mathrm{l}$ of positive controls for 30 minutes. Dilute samples ( $10 \mu 1$ sample to $40 \mu \mathrm{l}$ of sample diluent), and incubate for 30 minutes at $37^{\circ} \mathrm{c}$. After aspiration of the fluids and five successive washing steps, $50 \mu \mathrm{l}$ of Horseradidish peroxidase ( HRP) conjugate was then added and incubate for 30 minutes and cover the plate with a sealer. Plates were washed again to discard unbound (HRP) conjugate, TMB substrate is then added and color developed. The reaction was stopped by addition of acidic stop solution and color change into yellow that can be measured at $450 \mathrm{~nm}$. The OD of an unknown samples were compared 
with the OD of the negative and positive controls in order to determine the presence of Lep IgG.

\section{RESULTS:}

1. Identity: The parvovirus was identical in three batches.

2. Sterility: The three batches of tested vaccine were free from aerobic, an aerobic bacteria, Fungi, Mycoplasma and Salmonella contamination.
3. Completion of inactivation: The three batches of the tested vaccines have no residual infective virus as there is no evidence of infection in inoculated eggs at either passage.

4. Safety: The three batches of the tested vaccine were safe. (There is no undesirable local or systemic reaction occur).

5. Detection of humeral immune response among vaccinated ducks by ELISA:

Table 1: Humeral response among the vaccinated ducks:

\begin{tabular}{|c|c|c|c|c|c|c|c|c|}
\hline \multirow[b]{3}{*}{$\begin{array}{l}\text { Serum } \\
\text { sample }\end{array}$} & \multicolumn{8}{|c|}{ OD of the tested sample } \\
\hline & \multicolumn{2}{|c|}{ Batch1 } & \multicolumn{2}{|c|}{ Batch2 } & \multicolumn{2}{|c|}{ Batch3 } & \multicolumn{2}{|c|}{ control } \\
\hline & OD & Result & OD & Result & OD & Result & OD & Result \\
\hline 1 & 0.46 & $+\mathrm{ve}$ & 0.48 & tve & 0.39 & $+v e$ & 0.192 & $-\mathrm{ve}$ \\
\hline 2 & 0.39 & $+\mathrm{ve}$ & 0.40 & $+\mathrm{ve}$ & 0.37 & $+\mathrm{ve}$ & 0.100 & $-\mathrm{ve}$ \\
\hline 3 & 0.34 & $+\mathrm{ve}$ & 0.37 & $+\mathrm{ve}$ & 0.38 & $+\mathrm{ve}$ & 0.122 & $-\mathrm{ve}$ \\
\hline 4 & 0.41 & + ve & 0.42 & $+\mathrm{ve}$ & 0.41 & $+\mathrm{ve}$ & 0.182 & $-\mathrm{ve}$ \\
\hline 5 & 0.44 & $+\mathrm{ve}$ & 0.48 & $+\mathrm{ve}$ & 0.40 & $+\mathrm{ve}$ & 0.172 & $-\mathrm{ve}$ \\
\hline 6 & 0.38 & $+\mathrm{ve}$ & 0.41 & $+\mathrm{ve}$ & 0.48 & $+\mathrm{ve}$ & 0.123 & $-\mathrm{ve}$ \\
\hline 7 & 0.36 & + +ve & 0.38 & $+\mathrm{eve}$ & 0.51 & + +ve & 0.112 & $-\mathrm{eve}$ \\
\hline 8 & 0.49 & $+\mathrm{ve}$ & 0.50 & $+\mathrm{ve}$ & 0.34 & $+\mathrm{ve}$ & 0.132 & $-\mathrm{ve}$ \\
\hline 9 & 0.37 & $+\mathrm{te}$ & 0.38 & $+\mathrm{ve}$ & 0.44 & $+\mathrm{ve}$ & 0.192 & $-\mathrm{eve}$ \\
\hline 10 & 0.35 & + ve & 0.39 & + ve & 0.35 & $+\mathrm{ve}$ & 0.172 & $-\mathrm{ve}$ \\
\hline
\end{tabular}

$\mathrm{OD}+\mathrm{ve}=1.358$

$\mathrm{OD}-\mathrm{ve}=0.193$

Cutoff value $=-$ ve control value $+0.15=0.193+0.15=0.34$

While OD sample < Cutoff value: Negative.

While OD sample $>$ Cutoff value: Positive.

Batch 1, 2, 3: Different three batches of commercial inactivated Parvovirus vaccine against Derzsy's disease. 
Table 2: Humeral responses to vaccination among the vaccinated chicks:

\begin{tabular}{|c|c|c|c|c|c|c|c|c|}
\hline \multirow[b]{3}{*}{$\begin{array}{l}\text { Serum } \\
\text { sample }\end{array}$} & \multicolumn{8}{|c|}{ OD of the tested sample } \\
\hline & \multicolumn{2}{|c|}{ Batch1 } & \multicolumn{2}{|c|}{ Batch2 } & \multicolumn{2}{|c|}{ Batch3 } & \multicolumn{2}{|c|}{ control } \\
\hline & OD & Result & OD & Result & OD & Result & OD & Result \\
\hline 1 & 0.44 & +ve & 0.46 & $+\mathrm{ve}$ & 0.39 & $+\mathrm{ve}$ & 0.172 & $-\mathrm{ve}$ \\
\hline 2 & 0.48 & $+\mathrm{ve}$ & 0.50 & $+\mathrm{ve}$ & 0.37 & $+\mathrm{ve}$ & 0.182 & $-\mathrm{eve}$ \\
\hline 3 & 0.41 & +ve & 0.43 & $+\mathrm{ve}$ & 0.47 & +ve & 0.183 & $-v e$ \\
\hline 4 & 0.45 & +ve & 0.47 & $+\mathrm{ve}$ & 0.45 & $+\mathrm{ve}$ & 0.182 & $-\mathrm{ve}$ \\
\hline 5 & 0.47 & tve & 0.49 & +ve & 0.50 & $+\mathrm{ve}$ & 0.172 & $-v e$ \\
\hline 6 & 0.39 & $+\mathrm{ve}$ & 0.42 & $+\mathrm{ve}$ & 0.43 & $+\mathrm{ve}$ & 0.123 & $-\mathrm{ve}$ \\
\hline 7 & 0.44 & +ve & 0.46 & $+\mathrm{ve}$ & 0.42 & $+\mathrm{ve}$ & 0.112 & $-v e$ \\
\hline 8 & 0.49 & $+\mathrm{ve}$ & 0.51 & $+\mathrm{ve}$ & 0.47 & $+\mathrm{ve}$ & 0.132 & $-\mathrm{ve}$ \\
\hline 9 & 0.46 & +ve & 0.48 & $+\mathrm{ve}$ & 0.43 & $+\mathrm{ve}$ & 0.192 & $-\mathrm{ve}$ \\
\hline 10 & 0.45 & $+\mathrm{ve}$ & 0.47 & $+\mathrm{ve}$ & 0.50 & $+\mathrm{ve}$ & 0.172 & $-\mathrm{eve}$ \\
\hline
\end{tabular}

$\mathrm{OD}+\mathrm{ve}=1.718$

$\mathrm{OD}-\mathrm{ve}=0.189$

Cutoff value $=$-ve control value $+0.15=0.189+0.15=0.339$

While OD sample < Cutoff value: Ngative.

While OD sample $>$ Cutoff value: Positive.

Batch 1, 2, 3: Different three batches of commercial inactivated Parvovirus vaccine against Derzsy's disease.

\section{DISCUSSION}

Infectious diseases are the biggest obstacle to the expansion and development of water fowl industry, and GPV is one of the most serious viral pathogens. Since stunted birds that recover from disease do not usually regain normal weight (Jestin et al., 1991a, Woolcock et al., 2000), Protection against the disease is crucial to prevent specifically serious economic losses in Muscovy duck rearing farms (Jestin et al., 1991a). At present stage, prevention and early detection are still effective ways to control disease. Many routine detection methods for GPV had been developed GPV isolations using embryonating goose eggs, or primitive goose embryo fibroblasts are widely used in virology diagnosis. PCR have been effectively applied for the rapid detection since they were developed in the late 1990s. Real-time PCR test was used as a highly sensitive and specific method for quantitatively detecting GPV DNA, and thus can detect this virus. Furthermore, agar diffusion test and Loop-Mediated isothermal amplification were reported for more simple detection of GPV infections. Indirect ELISA based on VP3 protein are commonly used for the detection of GPV antibodies. ELISA method was used to analyze the immune status of vaccinated flocks. 
The conventional ELISA used to develop assay for a serological survey was reported by Kardi and Szegletes (1996). The VN tests have been considered to be sensitive assays for the detection of antibodies against GPV or MDPV in ducks or geese, but these tests are very labor intensive, require at least a week to complete, and the technique requires experienced technicians for the checkpoint examination of the cytopathic effect. The ELISA based on recombinant proteins as a coating antigen for the detection virus infection is a simple, sensitive, and rapid method, and has been used widely for large-scale surveys. The ELISA with its high diagnostic sensitivity, represents adequate method Whether the ELISA may be suitable as a diagnostic test in epidemiological monitoring programmes.

Birds exposed to pathogens develop circulating antibodies that generally persist for several weeks after the antigen has been cleared. Detection of these antibodies is much more convenient than detecting cellular immunity, and a number of serologic assays are available to quantitate antibodies. Some of the commonly used serologic tests include agar gel precipitation test, virus neutralization test, immunofluorescence test, hem agglutination inhibition test, and enzyme linked immunosorbent assay (ELISA) (Thayer and Beard, 1998), however ELISA test is used most commonly for serologic monitoring (Sharma,1999).

The protective efficacy of a vaccine depends on its capability to induce a vigorous and long-lasting immunoresponse. The objective of this study was to assess the efficacy of commercial inactivated duck parvovirus vaccine in conventional ducklings by monitoring the antibody response of domestic Muscovy ducks after subcutaneous immunization comparing the humoral immune response between vaccinated Muscovy ducklings and vaccinated SPF chicks using ELISA.

Indirect enzyme-linked immunosorbent assays (ELISAs), as commercially available for chickens and turkeys (Office International des Epizooties, 2017), can be standardized easily, have the advantage of a possible high degree of automation concerning the operation and evaluation process, and are thus suitable for a high sample throughput.

Quality control results showed that the three batches of the inactivated vaccine were identical, free from aerobic, an aerobic bacteria, Fungi, Mycoplasma and Salmonella contamination and have no residual infective virus as there is no evidence of infection in inoculated eggs at either passage. There is no undesirable local or systemic reaction occur in safety groups.

Results of ten serum samples of four weeks post vaccinated Muscovy ducks (Experiment A) tested by ELISA for detection antibodies to GPV/MDPV, the results were positive for 10 serum samples for different three vaccine batches GPV/MDPV antibodies of four weeks PV. (As showed in table 1). Our finding agree with (Yun Zhang et al., 2010) who developed an ELISA (VP3-ELISA) using the VP3 protein as the coating antigen for the detection of antibodies to GPV in geese and antibodies to Muscovy duck parvovirus (MDPV) in Muscovy ducks and found that VP3-ELISA is a sensitive and specific method for detecting protective antibodies against GPV or MDPV. Also our finding agree with 
Woolcock et al.(2000) who reported that Elisa, IFAT and immunological microscopy as a serological tests provided evidence of (GPV or MDPV) antibodies were present in the sera of sick and recovered ducks, none of these tests is able to differentiate GPV and MDPV antibodies because the two viruses share many antigenic similarities. Also this finding agree with Jestin et al.(1990b) who reported a high sero conversion to parvovirus was observed in five and nine week old Muscovy duckling when using MDPV antigen in ELISA.

The poultry industry constitutes a significant sector of the world agriculture especially chickens that are the largest segment of the industry as they are more available and low cost than other poultry species. In addition to SPF chicks used in this study were free from any derived maternally antibodies that may interfere with vaccine evaluation.

Results of ten serum samples of four weeks post vaccinated SPF chicks (experiment B) tested by ELISA for detection antibodies to GPV/MDPV, the results were positive for 10 serum samples for GPV/MDPV antibodies of four weeks PV. Chickens are considered the most widely studied avian species showing some differences in immunological response (Abd-Alla et al., 2017).

As SPF chicks are non-susceptible to parvovirus infection, so the vaccine was act as foreign body that produce antibodies.

Recommendation: Muscovy ducks is the susceptible host for parvovirus up to approximately six weeks of age while SPF chicks is non susceptible host for parvovirus and we used it as a model for production of humeral antibodies.

\section{REFERENCES}

Abd-Alla, H.I., Sweelam, H.M., Mohamed, T.A., Gabr, M.M., El-Safty, M.M. and Hegazy, M.F. (2017). Efficacy of extracts and iridoid glucosides from Pentas lanceolata on humoral and cell-mediated immune response of viral vaccine. Med Chem Res 26:2196-2204.

Alexander, D.J. (1988). Newcastle disease. Kluwer, Boston, pp 347-365.

Egyptian standard regulations for evaluation of veterinary biologics, $3^{\text {rd }}$ Edition, 2017.

Glávits, R., Zolnai, A., Szabó, E., Ivanics, E., Zarka, P., Mató, T. and Palya, V. (2005). Comparative pathological studies on domestic geese (Anser anser domestica) and Muscovy ducks (Cairina moschata) experimentally infected with parvovirus strains of goose and Muscovy duck origin. Acta Vet Hung.; 53:73-89. doi: 10.1556/AVet.53.2005.1.8.

Gough, R. E. (2008). Parvovirus Infections. In Diseases of Poultry. Eds Y. M. SAIF, AM. FADLY, J. R. GLISSEN, L. R. MCDOUGALD, L. K. NOLAN, D. E. SWAYNE 12th edn. WileyBlackwell. pp 397-404.

Gough, R.E., (1984). Application of the agar gel precipitation and virus neutralization tests to the serological study of goose parvovirus. Avian Pathol. 13, 501-509.

Grzegorz, W., Wojciech, K. and Elżbieta, S. (2009).Genetic variance of Derzsy's 
disease strains isolated in Poland. J Mol Genet Med.; 3:210-216.

Jestin, V. (1990). Le point sur l'pizootie actuelle de maladie de Derzsy chez le canard de Barbarie. I,Aviculteur 516, 77-78.

Jestin, V. (1991). Actualite sur la maladie de Derzsy. Semaine Wterinaire 606,28.

Jestin, V., Lebras, M., Cherbonnel, M., Legall, G. \& Bennejean, G. (1991b). Diagnostic de la maladic de derzy 1,Aviculteur ,521,49-51.

Jestin, V., Lebras, M., Cherbonnel, M., Legall, G. \& Bennejean, G. (1991a) Isolement de virus de la maladie de Derzsy tres pathogenes chez le canard de Barbarie. Recueil de Medecine Veterinaire 167, 849-857.

Kardi, V., Szegletes, E., (1996). Use of ELISA procedures for the detection of Derzsy's disease virus of geese and of antibodies produced against it. Avian Pathol. 25, 25-34.

Kisary, J. (1977). Immunological aspects of Derzsy's disease in goslings. Avian Pathology 6, 327-334.

Kisary, J., Derzsy, D. \& Meszaros, J. (1978) .Attenuation of the goose parvovirus strain B. Laboratory and field trials of the attenuated mutant for vaccination against Derzsy's disease. Avian Pathology 7, 397-406.

Limn, C.K., Yamada, T., Nakamura, M., Takehara, K., (1996). Detection of goose parvovirus genome by polymerase chain reaction: distribution of goose parvovirus in Muscovy ducklings. Virus Res. 42, 167-172.

Office International des Epizooties. (2017). Newcastle disease. In Manual of Diagnostic Tests and Vaccines for Terrestrial Animals 6th, Vol. 1 (pp. 576-589). Paris: OIE.

Palya, V. J. (2011). Major Viral Diseases of Waterfowl and Their Control. Director of Scientific Support and Investigation Laboratory of CevaPhylaxia Veterinary Biologicals Co.in Budapest, the British Veterinary Poultry Association (BVPA)

Palya, V. J. (2013). Parvovirus infections of waterfowl. In Diseases of Poultry. EdsD. E. SWAYNE, J. R. GLISSEN, L. R. MCDOUGALD, L. K. NOLAN, D. L. SUAREZ, V. L. NAIR. 13th edn. Wiley-Blackwell. pp 444-454

Sharma, J. M. (1999). Introduction to poultry vaccines and immunity. Advances inVeterinary Medicine 41:481-494.

Takehara, K., Hyakutake, K., Imamura, T., Mutoh, K. and Yoshimura, M.(1994). Isolation identification, and plaque titration of parvovirus from Muscovy ducks in Japan Avian Dis. 38, 810815 .

Takehara, K., Nakata, T., Takizawa, K., Limn, C.K., Mutoh, K. and Nakamura, M., (1999).Expression of goose parvovirus VP1 capsid protein by a baculovirus expres-sion system and establishment of fluorescent antibody 
test to diagnose goose parvovirus infection. Arch. Virol. 144, 16391645.

Takehara, K., Ohshiro, T., Matsuda, E., Nishio, T., Yamada, T. \& Yoshimura, M. (1995). Effectiveness of an inactivated goose parvovirus vaccine in Muscovy ducks. Journal of Veterinary Medical Science 57, 1093-1095.

Thayer, S. G. and C. W. Beard. (1998). Serologic procedures in D. E. Swayne, J. R.Glisson, M. W. Jackwood, J. E. Pearson, and W. M. Reed (eds.). A Laboratory Manual for the Isolation and Identification of Avian Pathogens. Am Assoc. Avian Pathologists 4th ed. 225-266.

Wang, C.Y., Shieh1, H.K., Shieh, J.H., Ko, C.Y. and Chang, P.C., (2005). Expression of capsid proteins and non-structural proteins of waterfowl parvoviruses in Escherichia coli and their use in serological assays. Avian Pathol. 34, 376-382.

Woolcock P.R., Jestine V., Shivaprasad H.L. Zwingestein F., Arnauld C. ,McFarland M. D., Pedersen J. C.and Senne D. A. (2000). Evidence of Muscovy duck parvovirus in Muscovy ducklings in California.Vetrenary Record 146,6872.

Yun Zhang, Yongfeng Li a, Ming Liu, Dabing Zhang, Dongchun Guo, Chunguo Liu, Haidong Zhi Xiaomei Wang, Gang Li d,NaLi, Shiguo Liu , Wenhua Xiang and Guangzhi Tong. (2010). Development and evaluation of a VP3-ELISA for the detection of goose and Muscovy duck parvovirus antibodies. Journal of Virological Methods 163, 405-409. 